\title{
Constituintes sangüíneos de vacas da raça holandesa alimentadas com silagens de milho ou de capim-elefante
}

\author{
Blood constituents of holstein cows fed with corn or \\ elephant-grass silages
}

\author{
Moyses Calixto Junior ${ }^{1}$; Clóves Cabreira Jobim²*; \\ Geraldo Tadeu dos Santos ${ }^{3}$; Valter Harry Bumbieris Júnior ${ }^{4}$
}

\begin{abstract}
Resumo
O objetivo deste trabalho foi avaliar os efeitos do fornecimento de silagem de milho (Zea mays L.) e silagem de capim-elefante (Pennisetum purpureum Schum) na alimentação de vacas em lactação, sobre alguns dos constituintes sangüíneos (glicose, triglicerídeos e uréia). Os tratamentos foram três silagens (silagem de milho, silagem de capim-elefante com inoculante bacteriano, silagem de capim-elefante com inoculante enzimo-bacteriano). Foram utilizadas nove vacas da raça holandesa, com peso médio de 520 $\mathrm{kg}$, distribuídas em delineamento experimental de triplo quadrado latino simultâneo. As taxas de glicose sangüínea das vacas foram consideradas normais, independente do volumoso utilizado. Em relação aos níveis de triglicerídeos, verificou-se que estão abaixo do normal para os diferentes volumosos. Uma das razões seria o baixo nível de gordura na dieta. Os níveis sangüíneos de uréia observados nos três tratamentos são considerados normais. Não houve diferença significativa entre os volumosos em relação aos níveis sangüíneos de uréia, glicose e triglicerídeos.
\end{abstract}

Palavras-chave: Glicose, triglicerídeos, uréia

\begin{abstract}
The objective of this work was to evaluate the effects of corn (Zea mays L.) silage and elephant-grass (Pennisetum purpureum Schum) silage on the nutrition of cows during lactation, over some of the blood constituents (glucose, triglycerides and urea). The treatments were three silages (corn silage, elephantgrass silage with bacterial inoculating, elephant-grass silage with enzyme-bacterial inoculating). Nine Holstein cows, with a medium weight of $520 \mathrm{~kg}$, were distributed in experimental delineation of simultaneous triple Latin square. The blood glucose rates were considered normal, independents of the silage used. Concerning the triglicerides levels, it was verified that they are below normal to the different silages. One of the reasons would be the low fat level on the diet. The blood levels of urea observed on the three treatments are considered normal. There was not significant difference among the different kinds of silage in relation to the blood levels of urea, glucose and triglycerides.
\end{abstract}

Key words: Glucose, triglycerides, urea

\footnotetext{
1 Aluno de Doutorado do Programa de Pós-graduação em Zootecnia da Universidade Estadual de Maringá - UEM. E-mail: m.cjunior@bol.com.br

2 Prof. Associado do Departamento de Zootecnia da Universidade Estadual de Maringá - UEM. E-mail: ccjobim@uem.br

3 Prof. Titular do Departamento de Zootecnia da Universidade Estadual de Maringá - UEM. E-mail: gtsantos@uem.br

4 Prof. Adjunto do Departamento de Zootecnia da Universidade Estadual de Londrina - UEL. E-mail: jrbumbieris@uel.br

* Autor para correspondência 


\section{Introdução}

Tradicionalmente, o material mais utilizado para ensilagem é a planta de milho, devido sua composição química preencher as exigências para confecção de uma boa silagem como, com teor de matéria seca entre 30 e $35 \%$, e no mínimo de $3 \%$ de carboidratos solúveis na matéria original, baixa capacidade tampão e por proporcionar uma boa fermentação microbiana (NUSSIO et al., 2001).

Uma das alternativas para ensilagem seria o aproveitamento do excedente de produção nas pastagens, bem como das capineiras, inclusive como forma de melhorar o manejo destas. Dentre as gramíneas forrageiras tropicais, o capim-elefante (Pennisetum purpureum Schum.) destaca-se para produção de silagem devido ao seu potencial produtivo e sua composição em termos de carboidratos solúveis, que é mais elevado quando comparado a outros capins

Atualmente, o uso de aditivos na confecção de silagem de gramíneas tropicais vem sendo freqüente, em várias regiões do Brasil. Os inoculantes bacterianos e enzimáticos têm alcançado grande evidência no mercado, principalmente devido ao aumento do uso de silagens de capins. Os inoculantes bacterianos buscam aumentar a velocidade e o padrão de fermentação por meio do aumento da população das bactérias ácido láticas, enquanto que as enzimas presentes nos inoculantes agem na parede celular disponibilizando maior quantidade de açúcares para fermentação, podendo até melhorar a digestibilidade da silagem, mas poucos estudos foram feitos no sentido de avaliar esses efeitos (VILELA, 1998).

De acordo com Jobim et al. (2007) além de todas as avaliações químicas, o que permite realmente conhecer as características qualitativas de uma silagem é o seu valor nutritivo que pode ser traduzido em consumo voluntário e conseqüentemente resposta produtiva do animal.

Os constituintes do plasma sangüíneo têm relação direta com a composição química e a digestibilidade dos componentes da dieta. Desta forma, as diferentes fontes de volumosos para vacas em lactação apresentam efeitos sobre a composição do plasma e, em conseqüência, sobre a composição do leite, determinando, em parte, a qualidade desse produto.

Aavaliação da composição sangüínea relacionada a lipídeos, carboidratos e proteínas, pode ser usada como indicador da saúde da vaca leiteira, para aprimoramento do padrão nutricional de rebanho, corrigindo desequilíbrios nutricionais, melhorando a saúde e, conseqüentemente, a produtividade.

A proteína é o primeiro nutriente limitante para produção de leite, particularmente para vacas em início de lactação (BEAULIEU; OLUBOBOKUN; CHRISTENSEN, 1990). Apenas uma limitada quantidade de proteína pode ser mobilizada, e os animais dependem em grande parte do alimento ingerido e da fermentação ruminal para fornecer os nutrientes necessários à produção de leite (SATTER; ROFFER, 1975; ORSKOV; REID; McDONALD, 1981; LENG; NOLAN, 1984). Já a uréia é um componente comum no sangue e nos outros fluídos do corpo onde sua formação tem origem no fígado pela conversão da amônia. A amônia é tóxica e se não existisse essa conversão da amônia para uréia, no fígado, o organismo se tornaria doente a cada ingestão de alimento protéico. A uréia é então excretada do corpo pela urina e pelo leite, no caso de vacas em lactação (MORRISON; MACKIE, 1996).

A uréia difunde-se no tecido do corpo em meio fluído como o sangue, constituindo-se num componente normal do leite e inclui parte do nitrogênio não protéico. As concentrações de uréia no sangue variam e são influenciadas pelo aporte de proteína e de energia e pela excreção urinária. Animais utilizando dietas ricas em proteína, com alto consumo, e não sincronismo entre a degradação da proteína e de carboidratos no rúmen, normalmente levam a maior concentração de uréia no sangue devido o não aproveitamento adequado da proteína (OLTNER; WIKTORSSON, 1983). 
O nível sangüíneo médio de uréia tido como normal é de 5 a $20 \mathrm{mg} / \mathrm{dL}$ (ANDREOTI, 1998). Em vacas leiteiras, a uréia no sangue irá refletir não só no catabolismo de proteína pelos tecidos, mas também no catabolismo de proteínas no rúmen pelas bactérias. A degradação ruminal de proteína libera amônia que pode ser utilizada pelos microrganismos do rúmen ou pode ser absorvida na corrente sangüínea. A amônia absorvida do rúmen deve ser convertida em uréia para desintoxicação (ANDREOTI, 1998). Assim, em vacas leiteiras, há duas maneiras que podem elevar a uréia no sangue: a primeira é pela degradação de proteína no rúmen, e a segunda pela degradação de proteína nos tecidos (em nível celular).

Os ruminantes têm basicamente a mesma exigência de glicose para o seu metabolismo que outras espécies, embora o nível de glicose encontrado no sangue seja de 40 a 60 mg/dL (FRASER, 1991), o que corresponde praticamente à metade do nível encontrado nos outros animais. Existem no mínimo cinco tecidos que exigem glicose: o tecido nervoso, o tecido muscular, o tecido adiposo, as glândulas mamárias e o feto. $\mathrm{O}$ sistema nervoso central do ruminante tolera períodos longos de hipoglicemia (18 mg de glicose/dL no sangue/6 h) sem efeitos deletérios.

Durante a lactação a glândula mamária tem exigência adicional de glicose para síntese de lactose e glicerol, além da necessidade de NADPH para síntese de ácidos graxos a partir do acetato. $\mathrm{O}$ maior precursor de ambas as unidades de lactose é a glicose sangüínea. Alguns experimentos sugerem que aproximadamente $80 \%$ da lactose do leite origina-se da glicose (HANDWICK; LINZEL; MEPHAN, 1963) e cerca de $12 \%$ da lactose é formada por glicogênio a partir da proteína.

Os lipídios dietéticos estão presentes principalmente em forma esterificada como mono e digalactoglicerídeos, quando o animal alimenta-se exclusivamente de forragem, e, como triglicerídeos, se o concentrado é o principal componente da dieta (SILVA, 1979).
Após o período de aleitamento os lipídeos apresentam apenas uma pequena parcela da dieta da maioria dos animais. Todavia o metabolismo das gorduras é de maior importância no campo da nutrição, tanto pelas funções vitais desempenhadas por ácidos graxos específicos como também pela intensa formação de gordura que ocorre no organismo, para a engorda, secreção do leite, além de outras funções fisiológicas (SILVA, 1979).

A distribuição dos lipídios na digesta do rúmen tem sido bastante estudada e em geral a fração lipídica microbiana está entre 10 e 20\% do total de lipídeos da digesta, havendo geralmente predominância de lipídeos nos protozoários os quais podem ser três vezes mais ricos em lipídeos. O restante dos lipídeos da digesta estão ligados a partículas alimentares ou em células livres no líquido ruminal. Dietas a base de concentrado devem produzir digesta mais rica em lipídeo do que àquelas que contém mais volumoso (KEENEY, 1970).

O objetivo deste trabalho foi avaliar o efeito do fornecimento de silagem de milho ou silagem de capim-elefante na alimentação de vacas da raça holandesa, sobre alguns dos constiuíntes sangüíneos.

\section{Material e Métodos}

O experimento foi realizado no setor de Bovinocultura de Leite da Fazenda Experimental de Iguatemi (FEI), pertencente à Universidade Estadual de Maringá, situada no município de Maringá. Foram avaliados os efeitos do uso de silagem de milho (Zea mays L.) e de silagem de capimelefante (Pennisetum purpureum Schum) sobre os componentes do plasma sangüíneo de vacas da raça holandesa, em início de lactação. A silagem de milho foi confeccionada na Fazenda Experimental de Iguatemi sem uso de inoculantes. Já o capimelefante, cultivar Cameroon, foi ensilado em silos trincheiras, após 70 dias de crescimento, com uso de inoculantes comerciais. Foram confeccionados dois silos com capacidade de 10 toneladas cada, sendo 
um com aplicação de inoculante bacteriano e outro com inoculante enzimo-bacteriano.

Foram utilizadas nove vacas da raça holandesa, multíparas, em início de lactação, com peso médio de $520 \mathrm{~kg}$. Os animais foram mantidos em confinamento total durante todo o período experimental, em boxes individuais, com piso de borracha, cocho para alimentação e bebedouros. As vacas foram alimentadas três vezes ao dia, sendo o volumoso distribuído às $8 \mathrm{~h} 00$ e às $17 \mathrm{~h} 00$, e o concentrado em três vezes, 8 h00 (35\%), $13 \mathrm{~h} 00$ (30\%) e 17h00 (35\%), com uma dieta isoprotéica e isoenergética ajustada para produção de leite e condição (peso) corporal. A composição média das rações e a composição química dos volumosos utilizados na alimentação dos animais são apresentados nas (Tabelas 1 e 2).

Tabela 1. Composição percentual das rações experimentais, teor de proteína bruta (PB), extrato etéreo (EE) e nutrientes digestíveis totais (NDT) nas rações.

\begin{tabular}{llll}
\hline Composição & SCE-IB $^{1}$ & SCE-IEB $^{2}$ & S.MILHO \\
\hline SCE-IB & & & 60,75 \\
SCE-IEB & 56,54 & & \\
S.MILHO & & 56,99 & 17,66 \\
Milho Grão & 19,56 & 19,35 & 15,25 \\
F.Soja & 16,88 & 16,71 & 3,93 \\
F.Trigo & 4,34 & 4,30 & 0,71 \\
Bicarbonato Sódio & 0,78 & 0,77 & 0,84 \\
Calcário & 0,93 & 0,92 & 0,43 \\
Fosfato Bicálcico & 0,48 & 0,47 & 0,20 \\
Romivix & 0,22 & 0,22 & 0,16 \\
Sal comum & 0,17 & 0,17 & 0,08 \\
Roligomix & 0,09 & 0,09 & 14,30 \\
\hline PB Total (\%) & 13,94 & 14,06 & 3,11 \\
EE Total (\%) & 2,67 & 2,58 & 70,54 \\
NDT (\%) & 67,80 & 68,16 & \\
\hline
\end{tabular}

Onde: ${ }^{1} \mathrm{SCE}-\mathrm{IB}$ - Silagem de capim-elefante com inoculante bacteriano

${ }^{2} \mathrm{SCE}-\mathrm{IEB}$ - Silagem de capim-elefante com inoculante enzimo-bacteriano

Foram estudados os seguintes tratamentos: silagem de capim-elefante confeccionada com aplicação de inoculante bacteriano Propiolact MS01, produzido pela Lallemand S.A., composto por lactobacillus pantarum MA 18/5U (3.10 $\left.{ }^{10} \mathrm{UFC} / \mathrm{g}\right)$ e Propionibacterium MA 26/4U (3.10 $\left.{ }^{10} \mathrm{UFC} / \mathrm{g}\right)$ na dosagem de $5 \mathrm{~g}$ por tonelada de forragem; silagem de capim-elefante confeccionada com inoculante enzimo-bacteriano Bacto Silo produzido pela Katec e silagem de milho.

Para a confecção das silagens de capim-elefante, utilizou-se uma área de capineira estabelecida com cv. Cameroon. A área foi roçada para uniformizar o stand e após 15 dias foram aplicados $150 \mathrm{Kg} / \mathrm{ha}$ de
$\mathrm{N}$ na forma de uréia. Após 70 dias de crescimento, efetuou-se o corte para a confecção da silagem. Para a produção de silagem de milho, utilizou-se a variedade AG5011.

Nas silagens, foram determinados os teores de matéria seca (MS), proteína bruta (PB), fibra bruta (FB), fibra em detergente neutro (FDN), fibra em detergente ácido (FDA) e lignina segundo Van Soest (1994), extrato etéreo (EE), cinzas, e celulose, segundo procedimento analítico recomendado por Silva e Queiroz (2002). Também foram determinados os valores de $\mathrm{pH}$ e nitrogênio amoniacal $\left(\mathrm{N}-\mathrm{NH}_{3}\right)$ segundo Phillip e Fellner (1992) e os nutrientes digestíveis totais (NDT), estimados a partir da 
composição dos alimentos, de acordo com a equação proposta por Kearl (1982): (\%NDT $=-21,9391+$ $1,538 * \% \mathrm{~PB}+0,9736 * \% \mathrm{ENN}+3,0016 * \% \mathrm{EE}+$ $0,4590 * \% \mathrm{FB})$.

Durante o período experimental, foram feitas coletas de fezes para a avaliação da digestibilidade da MS e da FDN, por meio da FDN indigestível, a qual foi utilizada como indicador nas fezes. Foram feitas amostragens das silagens, concentrado, sobras e fezes, após a secagem em estufa a $55^{\circ} \mathrm{C}$ por 72 horas, que foram moídas em peneira com crivo de $5 \mathrm{~mm}$ de diâmetro e pesados de 6 a $7 \mathrm{~g}$ (base na MS) desses componentes. Depois, foram colocados em sacos de náilon do tipo ANKOM de $10 \mathrm{~cm} \times 17 \mathrm{~cm}$, com poros de aproximadamente 53 microns. As amostras foram incubadas em 2 vacas fistuladas no rúmen por 6 dias, sendo que os sacos foram presos a um cordão de náilon com $30 \mathrm{~cm}$, preso à tampa da cânula e ancorados com peso de $0,5 \mathrm{~kg}$ presos à extremidade do cordão de náilon. Todas as amostras, em cada vaca, foram incubadas em duplicata. Após a remoção, no tempo de incubação, os sacos foram lavados ligeiramente em água corrente e em seguida todos os sacos foram lavados em máquina de lavar durante 5 ciclos por 10 minutos. Após a lavagem à máquina, todos os sacos foram secos em estufa de ar forçado a $55^{\circ} \mathrm{C}$ por 72 horas e pesados para determinação do desaparecimento da matéria seca (MS).

O período experimental foi de aproximadamente 63 dias, divididos em 3 períodos de 21 dias (14 dias de adaptação e 7 dias de coleta de dados), referente à produção e à qualidade do leite. No final do período de coleta, foi coletado uma amostra de, aproximadamente, $15 \mathrm{~mL}$ de sangue, de cada animal, em jejum pela manhã, em recipiente com heparina, imediatamente colocadas em gelo e encaminhadas ao Laboratório de Análises Clínicas da Universidade Estadual de Maringá, para determinação dos níveis plasmáticos de triglicerídeos, de glicose e de uréia. O sangue para análise foi coletado por punção da veia jugular esquerda, com a utilização de uma agulha, colocado em tubo heparinado e mantido em recipiente térmico com gelo.

Para determinação dos teores de glicose sangüíneo, foi utilizado o método enzimático glicose oxidase/peroxidase (TRINDER, 1969). Os teores de uréia foram determinados pelo método enzimático uréase/glutamato desidrogenase (TALKE; SCHUBERT, 1965) e os teores de triglicerídeos foram determinados pelo método enzimático glicerol-fosfato-oxidase/peroxidase

(BUCOLO; DAVID, 1973).

A análise estatística dos dados obtidos foi realizada de acordo com o modelo:

$$
\mathrm{Y}_{\mathrm{ijk}}=\mu+\mathrm{Q}_{\mathrm{i}}+\mathrm{V}_{\mathrm{j}} / \mathrm{Q}_{\mathrm{i}}+\mathrm{S}_{\mathrm{i}}+\mathrm{A}_{\mathrm{k}}+\mathrm{e}_{\mathrm{ijk}}
$$

Onde:

$\mathrm{Y}_{\mathrm{ijk}}=$ observação referente a vaca $\mathrm{j}$ na semana $\mathrm{i}$ recebendo o volumoso $\mathrm{k}$.

$\mu=$ constante geral.

$\mathrm{Q}_{\mathrm{i}}=$ quadrado latino.

$\mathrm{V}_{\mathrm{j}} / \mathrm{Q}_{\mathrm{i}}=$ efeito da vaca $\mathrm{j}$ no quadrado latino.

$\mathrm{S}_{\mathrm{i}}=$ efeito da semana $\mathrm{i}, \mathrm{i}=1,2,3$.

$\mathrm{A}_{\mathrm{k}}=$ efeito do alimento $\mathrm{k}, \mathrm{k}=1,2,3$.

$\mathrm{e}_{\mathrm{ijk}}=$ erro aleatório associado a cada observação.

\section{Resultados e Discussão}

A composição químico-bromatológica das silagens estão apresentadas na Tabela 2. Os valores obtidos para PB nas silagens SCE-IB e SCE-IEB podem ser considerados baixos se comparados aos encontrados na literatura (TOSI et al., 1999; FERRARI JÚNIOR; LAVEZZO, 2001), com valores entre 11,0 e 7,1.

O teor protéico das silagens foi muito próximo dos valores encontrado na forragem fresca (média 5,61\% PB), o que demonstra que esse baixo valor não foi proveniente de perdas no silo, mas sim do 
próprio material ensilado. Isto pôde ser confirmado pelo teor de nitrogênio amoniacal $\left(\mathrm{N}-\mathrm{NH}_{3}\right)$ expresso como porcentagem do nitrogênio total (Tabela 2).

$O$ baixo teor de PB na forragem pode ser atribuído, entre outros fatores, à deficiência, principalmente de fósforo, porque a deficiência desse nutriente pode reduzir a síntese de ácido nucléico e de proteína, diminuindo a acumulação de compostos nitrogenados nos tecidos.

Tabela 2. Composição químico-bromatológica (\% da MS) das silagens de capim-elefante e da silagem de milho.

\begin{tabular}{|c|c|c|c|}
\hline Variáveis & SCE-IB $^{1}$ & SCE-IEB $^{2}$ & S.MILHO \\
\hline MS & 20,59 & 22,05 & 32,94 \\
\hline PB & 4,68 & 5,20 & 6,85 \\
\hline EE & 2,57 & 2,40 & 2,93 \\
\hline FDN & 74,02 & 71,69 & 54,96 \\
\hline FDA & 45,89 & 42,95 & 30,33 \\
\hline CEL & 36,42 & 34,47 & 24,80 \\
\hline HM & 28,13 & 28,74 & 24,63 \\
\hline LIG & 7,43 & 6,94 & 4,90 \\
\hline FB & 30,13 & 29,41 & 20,63 \\
\hline CINZA & 6,48 & 6,77 & 6,42 \\
\hline NDT & 59,19 & 58,98 & 65,08 \\
\hline ENN & 56,14 & 56,22 & 63,16 \\
\hline $\mathrm{N}^{-\mathrm{NH}_{3}}(\% \mathrm{~N}$ Total $)$ & 20,0 & 16,2 & 8,3 \\
\hline $\mathrm{pH}$ & 4,25 & 4,14 & 3,86 \\
\hline DIVMS $^{3}(\%)$ & 61,39 & 65,85 & 67,30 \\
\hline $\operatorname{DIVPC}^{4}(\%)$ & 51,67 & 58,73 & 64,46 \\
\hline
\end{tabular}

Onde: ${ }^{1}$ SCE-IB - Silagem de capim-elefante com inoculante bacteriano

${ }^{2}$ SCE-IEB - Silagem de capim-elefante com inoculante enzimo-bacteriano

CELULOSE $=($ FDA-LIGNINA)

HEMICELULOSE $=($ FDN-FDA $)$

${ }^{3}$ DIVMS - Digestibilidade in vitro da matéria seca

${ }^{4}$ DIVPC - Digestibilidade in vitro da parede celular

O valor energético das silagens, expressos em NDT, foi próximo aos relatados por Roston e Andrade (1992), cujo valor do NDT para a silagem de capim-elefante está entre 54 a $60 \%$, enquanto que a silagem de milho varia de 56 a $66 \%$.

A avaliação das perdas nas silagens de capimelefante mostrou que na SCE-IB a perda foi de $16,57 \%$ e para a SCE-IEB foi de $13,57 \%$, ficando abaixo das perdas apresentadas por Faria (1986), para o qual silagens com teores de MS próximos a $20 \%$ as perdas mínimas variaram de 18 a $23 \%$.

Considerando-se os valores de $\mathrm{pH}, \mathrm{N}_{-} \mathrm{NH}_{3}$ e a estimativa de perdas para as silagens de capim- elefante, pode-se deduzir que a qualidade de fermentação foi adequada com o uso de inoculante bacteriano ou de inoculante enzimo-bacteriano.

Os valores de glicose, triglicrídeos e uréia no plasma sangüíneo, encontrados em vacas da raça holandesa alimentadas com diferentes silagens encontram-se na Tabela 3.

Sabe-se que a glicose é responsável por inúmeras funções no organismo do ruminante e uma alteração na taxa de glicose sangüínea seria um indicativo de problemas no organismo do animal. Segundo Fraser (1991) os valores de glicose no sangue de vacas, na faixa de variação considerada normal, 
estão entre 42 e $74 \mathrm{mg} / \mathrm{dL}$. Assim sendo, a taxa de glicose sangüínea das vacas foi considerada normal independente da silagem utilizada.

Observou-se que a taxa de glicose sangüínea para as vacas alimentadas com silagem de milho foi mais elevada em relação àquelas alimentadas com silagem de capim-elefante, porém, não houve diferença $(\mathrm{P}>0,05)$ entre as silagens testadas.
Isto pode ser atribuído às quantidades de grãos ingeridos via silagem. Vacas alimentadas com altas quantidades de grãos têm o padrão de fermentação ruminal alterado, resultando em maiores produções de propionato, o qual juntamente com o aumento do fluxo de amido para o intestino pode contribuir para aumento dos níveis de glicose no sangue.

Tabela 3. Efeito da dieta na concentração de glicose, triglicerídeos e uréia no plasma sangüíneo de vacas em lactação.

\begin{tabular}{lllllll}
\hline Variáveis & SCE-IB $^{1}$ & SCE-IEB $^{2}$ & S.MILHO & P & DP & CV (\%) \\
\hline Glicose (mg/dL) & 46,78 & 42,22 & 47,44 & NS & 7,866 & 12,408 \\
Triglicerídeos (mg/dL) & 5,78 & 6,89 & 6,00 & NS & 3,566 & 46,764 \\
Uréia (mg/dL) & 17,20 & 14,93 & 14,98 & NS & 7,464 & 17,850 \\
\hline
\end{tabular}

Onde: ${ }^{1}$ SCE-IB - Silagem de capim-elefante com inoculante bacteriano

${ }^{2}$ SCE-IEB - Silagem de capim-elefante com inoculante enzimo-bacteriano $\mathrm{P}<0,05$

Dhiman, Kleinmans e Tessmann (1991), trabalhando com animais da raça holandesa, observaram que o aumento da quantidade de grãos na dieta aumentou a concentração de glicose no sangue, e que a concentração de glicose no sangue foi mais baixa no início da lactação.

Constatou-se que não houve efeito da silagem $(\mathrm{P}>0,05)$ sobre a concentração de triglicerídeos no plasma. O nível considerado normal de triglicerídeos sangüíneos é de $18 \mathrm{mg} / \mathrm{dL}$ (BYERS; SCHELLING, 1993). Verifica-se dessa forma, que os níveis de triglicerídeos sangüíneos encontrados (Tabela 3), para as diferentes silagens estudadas estão abaixo do normal. Uma das razões possíveis para este resultado seria o baixo nível de gordura na dieta (Tabela 1), onde recomenda-se a utilização de até $7 \%$ de lipídeos na ração total sem interferir na digestão da fração fibra.

Esses dados são similares aos verificados por Arruda et al. (2008), que também encontraram baixa concentração de triglicerídeos no sangue de vacas alimentadas com feno de alfafa, tifton- 85 e silagem milho e que segundo esses autores, o fator principal seria o baixo teor de gordura na dieta.

Com relação aos níveis sangüíneos de uréia, não houve efeito $(\mathrm{P}>0,05)$ entre os tratamentos, obtendo-se valor médio de $15,7 \mathrm{mg} / \mathrm{dL}$ para os três regimes alimentares (Tabela 3 ). Estes valores estão dentro do nível normal médio de uréia no sangue que é de 5-20 mg/dL (ANDREOTTI, 1998). Esses valores indicam que o teor de protéico das rações foram adequados, ou seja, não houve excesso de proteína bruta na dieta. De acordo com Fergurson e Chalupa (1989) e Garcia-Bojalil, Staples e Risco (1998), dietas com excesso de PB ou PDR, falta de carboidratos fermentáveis ou assincronia entre degradação de carboidratos e disponibilidade de energia promovem grande concentração de uréia no sangue e/ou excreção de uréia no leite e na urina. 
Arruda etal.(2008), observaramalta concentração de uréia no sangue de vacas em lactação, alimentadas com diferentes volumosos. Encontraram valores médio de 47,5 mg/dL, e concluíram que esta alta concentração de uréia foi devido ao elevado teor de proteína bruta da dieta, com valor médio de 19\% de PB.

Segundo Jobim (2010), a degradação de proteína da silagem resulta no aumento da ingestão de nitrogênio não protéico com conseqüente redução na ingestão de proteína verdadeira, quando comparada à forragem não fermentada. Portanto, faz-se necessário prevenir o acúmulo de amônia no rúmen. Silagens mal conservadas podem apresentar níveis elevados de nitrogênio solúvel e/ou nitrogênio total.

\section{Conclusões}

Os resultados permitem concluir que não houve efeito das silagens de milho ou de capim-elefante nos níveis sangüíneos de glicose, de uréia e de triglicerídeos.

\section{Referências}

ANDREOTTI, F. L. Mun-milk urea nitrogen. Maringá: Revisão Bibliográfica-PPZ-UEM, 1998, 10 p.

ARRUDA, D. S. R.; CALIXTO JUNIOR, M.; JOBIM, C. C.; SANTOS, G. T. Efeito de diferentes volumosos sobre os constituintes sangüíneos de vacas da raça holandesa. Revista Brasileira de Saúde e Produção Animal, Salvador, v. 9, n. 1, p. 35-44, 2008.

BEAULIEU, J. A.; OLUBOBOKUN, J. A.; CHRISTENSEN, D. A. The utilization of canola and its contituents by lactating dairy cows. Animal Feed Science and Technology, Amsterdam, v. 80, n. 3/4, p. 289-300, 1990.

BUCOLO, G.; DAVID, H. Quantitative determination of serum triglycerides by the use of enzymes. Clinical Chemistry, New York, v. 19, n. 5, p. 476-482, 1973.

BYERS, F. M.; SCHELLING, G. T. Los lípideos em la nutriciónde los rumientes. In: $\mathrm{CHURCH}$, C. D. $E l$ Rumiante: fisiologia digestiva y nutrición. Zaragosa: Acribia, 1993. p. 339-356.
DHIMAN, T. R.; KLEINMANS, J.; TESSMANN, N. J. Effect of dietary forage : grain ratio on blood constituents in dairy cows. Journal of Dairy Science, Champaign, v. 74, n. 8, p. 2691-2695, 1991.

FARIA, V. P. Técnica de produção de silagem. In: CONGRESSO BRASILEIRO DE PASTAGENS, 8., 1986, Piracicaba. Anais... Piracicaba: FALQ, 1986. p. 119-144.

FERGUNSON, J. D.; CHALUPA, R. Symposium: interactions of nutrition and reproduction. Journal of Dairy Science, Champaign, v. 72, n. 2, p. 746-766, 1989.

FERRARI JÚNIOR, E.; LAVEZZO, W. Qualidade da silagem de capim-Elefante (Pennisetum purpureum Schum.) emurchecido ou acrescido de farelo de mandioca. Revista Brasileira de Zootecnia, Viçosa, v. 30, n. 5, p. 1424-1431, 2001.

FRASER, C. M. Manual merck de veterinária. 6. ed. São Paulo: Roca, 1991. 2169 p.

GARCIA-BOJALIL, C. M.; STAPLES, C. R.; RISCO,A. A. Protein degradabillty and calcium salts of long-chain fatty acids in the diets of lactating dairy cows: productive responses. Journal of Dairy Science, Champaign, v. 81, n. 5, p. 1374-1384, 1998.

HARDWICK, D. C.; LINZEL, J. L.; MEPHAN, T. B. The metabolism of acetate and glucose by the isolated perfused udder. 2. The contribution of acetate and glucose to carbon dioxide and milk constituents. Biochemical Journal, New York, v. 88, n. 2, p. 213-220, 1963.

JOBIM, C. C. Produção de forragens conservadas para alimentação de bovinos. In: SANTOS, G. T.; MASSUDA, E.M., KAZAMA, D.C.S.; JOBIM, C. C.; BRANCO, A.F. Bovinocultura Leiteira. bases zootécnicas, fisiológicas e de produção. Maringá: Eduem, 2010. p. 309- 356.

JOBIM, C. C.; NUSSIO, L. G.; REIS, R. A.; SCHMIDT, P. Avanços metodológicos na avaliação da qualidade da forragem conservada. Revista Brasileira de Zootecnia, Viçosa, v. 36, p. 101-119, 2007. Suplemento.

KEENEY, M. Phisiology of digestion and metabolism in the ruminant. Oriel Press. Newcastle. 1970. 489 p.

KEARL, L. C. Nutrient requirements of ruminant in development contries. Logan: Utah State University. 1982. $381 \mathrm{p}$.

LENG, R. A.; NOLAN, J. V. Protein nutrition of the lactating dairy cow. Nitrogen metabolism in the rumen. Journal of Dairy Science, Champaign, v. 67, n. 5, p. 1072-1089, 1984. 
MORRISON, M. E.; MACKIE, R. I. Nitrogen metabolism by ruminal microorganisms: current understanding and future perspectives. Aust. J. Agric. Res., Queensland, v. 47, n. 2, p. 227-246, 1996.

NUSSIO, L. G.; CAMPOS, F. P.; DIAS, F. N. Importância da qualidade da porção vegetativa no valor alimentício da silagem de milho. In: SIMPÓSIO SOBRE PRODUÇÃO E UTILIZAÇÃO DE FORRAGENS CONSERVADAS. 1., 2001, Maringá. Anais... Maringá: UEM, 2001. p. 319.

OLTNER, R.; WIKTORSSON, H. Urea concentration in milk and blood as influenced by feeding varying amounts of protein and energy to dairy cows. Livestock Production Science, Champaign, v. 10, n. 5, p. 457-467, 1983.

ORSKOV, E. R.; REID, G. W.; McDONALD, I. The effect of protein degradability and food intake on milk yield and composition in cows in early lactation. British Journal Nutrition, Cambridge, v. 45, n. 3, p. 547-555, 1981.

PHILLIP, L. E.; FELLNER, V. Effects of bacterial inoculation of high-moisture ear corn on its aerobic stability, digestion, and utilization for growth by beef steers. Journal of Animal science, Champaign, v. 70, n. 10, p. 3178-3187, 1992.

ROSTON, A. J.; ANDRADE, P. Digestibilidade de forrageiras com ruminantes: coletânea de informações. Revista Brasileira de Zootecnia, Viçosa, v. 21, n. 4, p. 647-663, 1992.
SATTER, L. D.; ROFFER, R. E. Nitrogen requeriment and utilization in dairy cattle. Journal of Dairy Science, Champaign, v. 58, n. 8, p. 1219-1236, 1975.

SILVA, D. J.; QUEIROZ, A. C. Análise de alimentos (métodos químicos e biológicos). 3. ed. Viçosa, MG: UFV, 2002. 235 p.

SILVA, J. F. C. Fundamentos de nutrição de ruminantes. Piracicaba: Livroceres, 1979. 384 p.

TALKE, H.; SCHUBERT, G. E. Enzymatsche Harnstoffbestimmung in Blut und Serum im optischen Test nach Warburg. Klin. Wochenschr, Springer Wien, v. 43, n. 174, p. 174-175, 1965.

TOSI, P.; MATTOS, W. R. S.; TOSI, H.; JOBIM, C. C.; LAVEZZO, W. Avaliação do capim-Elefante (Pennisetum purpureum Schum.) cultivar Taiwan A-184, ensilado com diferentes técnicas de redução de umidade. Revista Brasileira de Zootecnia, Viçosa, v. 28, n. 5, p. 947-954, 1999.

TRINDER, P. Determination of glucose in blood using glucose oxidase with a alternative oxygen acceptor. Ann. Clinical Biochemistry, New York, v. 6, n. 24, p. 24-27, 1969.

VAN SOEST, P. J. Nutritional ecology of of ruminant. Ithaca: Cornell University Press, 1994, 476 p.

VILELA, D. Aditivos para silagem de plantas de clima tropical. In: REUNIÃO ANUAL DA SOCIEDADE BRASILEIRA DE ZOOTECNIA, 35., 1998, Botucatu. Anais... Botucatu: SBZ, 1998. p. 73-107. 
